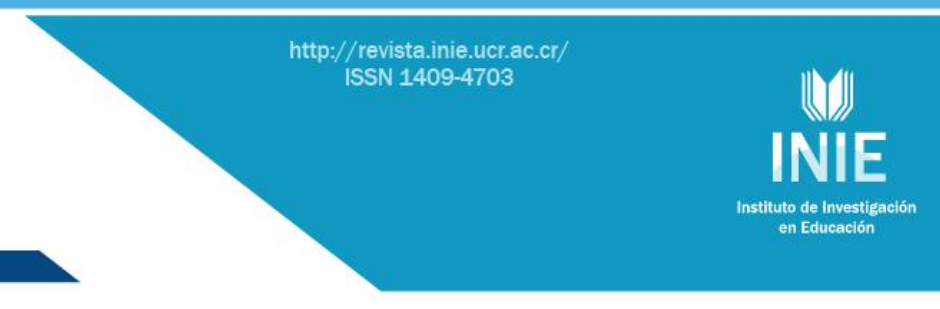

\title{
LOS PRIMEROS PASOS HACIA LA ENSEÑANZA ESPECIAL EN COSTA RICA \\ THE FIRST STEPS TOWARDS SPECIAL EDUCATION IN COSTA RICA
}

\author{
Volumen 15, Número 1 \\ Enero - Abril \\ pp. 1-28
}

Este número se publicó el $1^{\circ}$ de enero de 2015

DOI: dx.doi.org/10.15517/aie.v15i1.17726

Mariana Campos Vargas

Revista indizada en REDALYC, $\underline{\text { SCIELO }}$

Revista distribuida en las bases de datos:

CATÁLOGO DE LATINDEX, IRESIE, CLASE, DIALNET, DOAJ, E-REVIST@S, SHERPA/ROMEO, QUALIS, MIAR

Revista registrada en los directorios:

ULRICH'S, REDIE, RINACE, OEI, MAESTROTECA, PREAL, CLACSO 


\title{
LOS PRIMEROS PASOS HACIA LA ENSEÑANZA ESPECIAL EN COSTA RICA \\ THE FIRST STEPS TOWARDS SPECIAL EDUCATION IN COSTA RICA
}

\begin{abstract}
Mariana Campos Vargas ${ }^{1}$
Resumen: Este artículo presenta un estudio con base en fuentes documentales del Archivo Nacional de Costa Rica, que permitió conocer distintos factores que intervinieron en el surgimiento de la Enseñanza Especial en Costa Rica en el lapso 1880-1940, así como los diferentes actores que participaron en ese proceso. Además, a partir de expedientes disponibles de los estudiantes de la Escuela de Enseñanza Especial, se caracterizó a un segmento de esa población mediante algunas variables: edad, fecha y motivo de ingreso, lugar de nacimiento y residencia, número de hijos en el hogar, antecedentes familiares y situación laboral de los padres. Entre los hallazgos más destacables en este trabajo se constató un interés temprano en Costa Rica por observar y registrar las condiciones físicas, fisiológicas y mentales de la niñez en la escuela, así como, el propósito expreso en la legislación y desde iniciativas individuales, por fundar una Escuela de Enseñanza Especial en el país desde la década de 1930. Se concluye que desde la década de 1910 se dieron los primeros pasos que culminaron con la creación de la Escuela de Enseñanza Especial en Costa Rica en 1940.
\end{abstract}

Palabras clave: EDUCACIÓN ESPECIAL, LEGISLACIÓN, HISTORIA, DISCAPACIDAD, COSTA RICA

\begin{abstract}
This research was approached from the historical discipline, a study based on documentary sources of the National Archives of Costa Rica which allowed to know different factors involved in the emergence of special education in Costa Rica in the period 1880-1940, as well as stakeholders who participated in this process. In addition, from records of students of the School of Special Education, a segment of the school population has been characterized by age, date and reason of admission, place of birth and residence, number of children in the home, family background and employment status of the parents. Among the most noteworthy finds found an interest early to observe and record the physical, physiological and mental conditions of children in school, as well as, since the Decade of 1930, expressly in the legislation and from individual initiatives, interest in founding a school of special education. It is concluded that the first steps that led to the creation of the School of Special Education in Costa Rica in 1940 occurred since the 1910s.
\end{abstract}

Keywords: SPECIAL EDUCATION, LEGISLATION, HISTORY, DISABILITY, COSTA RICA

\footnotetext{
1 Profesora e Investigadora de la Escuela de Historia,

Universidad de Costa Rica.
}

Dirección electrónica: MARIANA.CAMPOS@ucr.ac.cr

Artículo recibido: 30 de mayo, 2014

Enviado a corrección: 6 de octubre, 2014

Aprobado: $1^{\circ}$ de diciembre, 2014 


\section{Introducción}

La presente investigación fue llevada a cabo desde la Escuela de Historia de la Universidad de Costa Rica y tiene como propósito general aportar al conocimiento sobre el tema de la discapacidad en nuestro país y particularmente pretende esclarecer las raíces que dieron sustento al surgimiento de la Escuela de Enseñanza Especial.

Se pretende responder a varias interrogantes: ¿Cuál fue el contexto nacional y las características del modelo educativo donde surgió la Enseñanza Especial en Costa Rica? ¿Cuáles actores promovieron su funcionamiento? ¿Cómo se financió? ¿Cuál fue el papel del Estado en ese proceso? ¿Quiénes eran los niños y las niñas que recibían sus servicios?

Partiendo de esas interrogantes, se formuló como objetivo general el siguiente: Conocer el contexto histórico y los actores involucrados en el surgimiento de la Enseñanza Especial en el país, así como a la población estudiantil, para identificar las políticas públicas puestas en marcha en el lapso en estudio. El primer objetivo específico fue identificar en el contexto nacional y en el modelo educativo vigente en el lapso 1870-1940 los factores que entraron en juego en el surgimiento de la Enseñanza Especial en Costa Rica para lograr una aproximación a las políticas públicas diseñadas para la atención de los escolares en condición de discapacidad en ese lapso. El segundo objetivo fue conocer a los actores que promovieron y le dieron fundamento a la Enseñanza Especial, así como, a la población escolar con el propósito de caracterizarla.

\section{Breve referente teórico}

La diversidad es consustancial al ser humano. Las personas en condición de discapacidad son un segmento de esa diversidad. No obstante, a través del tiempo y en distintos contextos, la forma en que el conjunto de la población define, percibe y se relaciona con ese grupo ha sido diferente, porque sus características, intereses y necesidades son distintas, esto debido a la interrelación que se da entre sus condiciones (físicas, sensoriales intelectuales, mentales) y su entorno social (limitación en la actividad y restricción para la participación).

En las sociedades occidentales, esa percepción y relación evolucionó en la Edad Moderna (siglos XV-XVIII) hacia el paradigma asistencial-institucional, mediante el cual se brindó atención y se segregó a la población en condición de discapacidad. En esa etapa, tuvo lugar el desarrollo de diferentes propuestas para educar a las personas con ceguera, sordera y mudez. Esas fueron las primicias de la educación para ese grupo. 
Durante esos siglos, el continente americano fue conquistado y colonizado por los europeos, por lo tanto, los conceptos intrínsecos del modelo asistencial-institucional estuvieron vigentes en tierras americanas, inclusive en el período posterior al momento en que tuvo lugar la ruptura con las potencias coloniales.

En el siglo XIX y parte del siglo XX, en Europa occidental, la evolución en la atención para las personas en condición de discapacidad, continúo bajo la asociación entre medicina y pedagogía, situación que propició la puesta en marcha de un modelo de rehabilitación, basado en la interdisciplinariedad, donde el médico se ocupaba de la deficiencia y el maestro de la tarea de educar. Así se fortaleció la educación para las personas en condición de discapacidad y tomó fundamento la Educación Especial, con un enfoque basado en la deficiencia, un concepto asistencial y bajo el principio de institucionalizar a la persona de manera segregada.

Tanto ese vínculo entre disciplinas -la medicina y la pedagogía-, como ese modelo, tuvieron influencia en diferentes lugares, en particular, en las antiguas colonias europeas en América, repúblicas que en el transcurso de los siglos $\mathrm{XIX}$ y $\mathrm{XX}$ mantuvieron ligámenes de carácter comercial, científico e intelectual con el viejo continente y Costa Rica no fue la excepción.

\section{Metodología}

La presente investigación histórica es de carácter descriptivo y explicativo. Se trata de responder a las interrogantes: ¿Cuándo, cómo y por qué surge la Enseñanza Especial en el país? y ¿Cuáles actores participaron de ese proceso y quiénes se beneficiaron? Para buscar un acercamiento a esas respuestas, se utilizó documentación y legislación del período en estudio y bibliografía, que hicieron referencia al modelo educativo, las leyes, los códigos y las iniciativas de actores individuales y colectivos. Además, para las primeras cuatro décadas de funcionamiento de la institución, se dispuso de un segmento de los expedientes de la población de la Escuela de Enseñanza Especial, que se trabajó con variables sociodemográficas, en un análisis descriptivo de los datos mediante distribución de frecuencias. Los datos de esos expedientes se organizaron en hoja Excel siguiendo el recorrido de la información establecida en cada expediente: fecha de ingreso a la institución, edad del estudiante, de los padres, lugar de nacimiento, lugar de residencia, oficio del padre y la madre, antecedentes familiares y motivo del ingreso a la escuela. Se procesó la información con porcentajes simples. Otro tipo de información no se procesó debido a la diversidad y al 
deterioro que presentó el expediente. Ese universo corresponde a una fracción de los alumnos que ingresaron a la institución en ese lapso, no obstante el interés consiste en examinar la fuente y proveer algunas referencias al respecto que denotan la importancia del expediente del estudiante.

\section{Resultados y análisis}

\subsection{Educación y salud en Costa Rica (1880's-1940)}

El vínculo que se estableció en materia de salud y educación en Costa Rica, constituye un punto de partida para explicar el contexto en el surgió la Enseñanza Especial en el país. Aspectos claves del modelo educativo y del devenir en las políticas de salud, son un preámbulo para comprender ese contexto y esa relación.

La educación en Costa Rica tuvo una trayectoria relevante como pilar de su desarrollo desde etapas tempranas ${ }^{2}$. Después de la independencia, los municipios y la iglesia católica heredaron de la etapa colonial su labor educativa, situación que se mantuvo hasta el momento en que la exportación de café, generó mayores recursos económicos y eso favoreció en algunas etapas, la centralización política y administrativa del Estado, situación que permitió una intervención un poco más directa en la educación en coyunturas claves (Molina, 2008, p. 184 y Quesada, 2005, pp. 10-12).

En ese mismo lapso, la iglesia también jugó un rol importante en la organización de juntas de sanidad e higiene, apoyada por diferentes grupos de filantropía y desde 1847 por los médicos de pueblo, mientras que, la construcción de infraestructura hospitalaria y de cañerías, complementó la labor en esa materia.

Los municipios, la iglesia y distintos organismos como el Protomedicato (1858), así como los esfuerzos de un Estado en formación, compartieron disposiciones y acciones en los ámbitos de salud y educación en el lapso de 1821 a 1870, una etapa en que se mantuvo una frontera agrícola abierta y accesible a la población campesina (colonización agrícola), lo cual permitió una estructura social no polarizada y con fuerte presencia de pequeños y medianos productores, pero que dificultó la alfabetización de la población (Molina, 2008, p. 199).

\footnotetext{
${ }^{2}$ Es importante mencionar que el sistema educativo es uno de los sectores de mayor antigüedad en el Estado costarricense, pues el ente de Instrucción Pública data de 1847, en ese momento adscrito a la Secretaría de Hacienda, Guerra y Marina hasta la promulgación de la Ley General de Educación Común (1886) que la ubicó como parte de la Secretaría Fomento y luego por Decreto Ejecutivo de 1928 se consolidó como Secretaría de Educación Pública hasta constituirse en Ministerio de Educación Pública en 1949. (Programa Estado de la Nación en Desarrollo Humano Sostenible, 2005, p. 47)
} 
A partir de 1870 comenzaron los cambios que culminaron con la reforma educativa de la década del ochenta en el siglo XIX, pues un círculo de políticos e intelectuales liberales promovieron la centralización, secularización y actualización del sistema educativo. De igual forma, una nueva institucionalidad fue impulsada para mejorar las condiciones de higiene y salud de la población costarricense.

El nuevo modelo educativo centralizado-secular, inició con la promulgación de la Ley Fundamental de Instrucción Pública de 1885 y un año después con la puesta en marcha de la Ley General de Educación Común. En ese lapso, la ley de 1885 afianzó la presencia del Estado en las escuelas públicas y particulares. Además, con la Ley de 1886, se centralizaron todas las tareas en la cartera de Instrucción Pública y se expandió, consolidó y secularizó la enseñanza primaria. También con esa legislación, fue reestructurada la enseñanza secundaria y se desarrolló la educación para adultos, las escuelas técnicas, comerciales y de oficios (Molina, 2008). Además, debido a la clausura de la Universidad de Santo Tomás en 1888, la formación y titulación de educadores la asumió la Escuela Normal en el año 1914.

Como señala Molina (2008, pp. 57-58), pese a sus limitaciones, ese modelo educativo tuvo repercusiones significativas en la sociedad costarricense, entre éstas, constituyó al sistema educativo como la base sobre la cual se estructuró la política social del Estado costarricense en el campo de la salud pública, dando paso a una institucionalidad que fue reforzada y que favoreció la relación entre los ámbitos de la salud y la educación como se verá de seguido.

A fines del siglo XIX, las labores en educación y salud, se llevaron a cabo desde diversas instancias y con la concurrencia de individuos y de grupos de profesionales como lo fue la Facultad de Medicina (1895-1940) (Palmer, 2005, pp. 65-66), en una fase en que el Estado costarricense se encontraba en un proceso de construcción, proceso que incluyó la creación de su estructura orgánica. Así se fue esbozando el camino que definió las instituciones rectoras en materia de educación y salud que se consolidaron en el lapso en estudio, donde destacaron la cartera de Instrucción Pública (1885), la Secretaría de Salubridad Pública (1927), la Caja Costarricense de Seguro Social (1941) y el Ministerio de Educación Pública (1949).

En esa época, la preocupación de los hacedores de la política pública en salud, se mantuvo entorno a enfermedades infecto-contagiosas, las de carácter respiratorio y del aparato digestivo, -ese fue el caso de la anquilostomiasis-. Para combatir esa enfermedad, se organizó una campaña que operó en el país entre $1910-1914$, antes de la llegada de la 
Comisión Internacional de Salud de la Fundación Rockefeller ${ }^{3}$, entidad que apoyó la continuidad de esa cruzada y la campaña contra la tuberculosis (Solano, 2008; Velázquez, 2006), aunque buena parte de sus recursos se reorientaron hacia la higienización en las escuelas (revisión médica, tratamiento dental, higiene en la infancia) (Palmer, 2009, p.408). Con ese propósito fue que se estableció el Departamento Sanitario Escolar, durante el gobierno de Alfredo González Flores (1914), lo que convirtió al sistema educativo en pilar de las políticas en salud.

La labor del Departamento Sanitario Escolar, resultó la instancia correspondiente, que se ocupó a partir de ese momento, de observar y registrar las particularidades de la población escolar costarricense, en una cobertura de carácter nacional y uniformando los formularios médicos.

\subsection{Exclusión, observación y registro}

La Ley General de Educación Común emitida en 1886, estableció en su primer capítulo, artículo primero que la "escuela primaria tiene por objeto favorecer y dirigir gradual y simultáneamente el desarrollo moral, intelectual y físico del educando", y de seguido, en el capítulo segundo en su artículo trece inciso dos estableció: "Están exentos de la asistencia a la escuela, los niños que por enfermedad física o mental no sean aptos para recibir la instrucción" (Ley General de Educación Común, 1886, pp. 1, 4)

En esos dos acápites de la Ley de 1886, quedó explícito, por una parte, las tres dimensiones que cobró la educación para la población escolar: su desarrollo moral, intelectual y físico, y por otra, su carácter excluyente, aspectos que definieron parte de las características al modelo educativo centralizado-secular que estuvo vigente hasta mediados del siglo XX.

Durante la administración González Flores, además de la creación del Departamento Sanitario Escolar, fue decretado el Reglamento del Cuerpo Médico Escolar e Inspección Médica e Higiénica de los establecimientos de Instrucción Pública. En ese reglamento afirmó que: "uno de los deberes primordiales del Estado es el de velar por la salud pública y el de procurar la difusión de las prácticas higiénicas con el objeto de prevenir los males que ocasiona la ignorancia”(...) También dijo que "la Escuela Primaria, al recibir al niño cuando

\footnotetext{
${ }^{3}$ La Facultad de Medicina de Costa Rica autorizó a los miembros designados por esa Fundación para ejercer tanto las ramas de la medicina de sus cargos en el país, como también la Dirección del Cuerpo Médico Escolar. (Gaceta Médica de Costa Rica, 1926, p. 331)
} 
está en pleno período de crecimiento debe ocuparse de su desarrollo físico tanto como de su desarrollo intelectual" y que para que las medidas higiénicas tuvieran eficacia era necesario el nombramiento de un médico director dependiente de la Secretaría de Instrucción Pública (Decreto Ejecutivo $\mathrm{N}^{\circ}$ 6, 1914).

El Cuerpo Médico Escolar, estuvo a cargo de un médico director, quien además contó con el apoyo de los médicos de pueblo. Sus dos tareas esenciales fueron vigilar la higiene en las escuelas (estado sanitario) y el cuidado de la salud de los alumnos (examen individual $)^{4}$, en una visita mensual como mínimo al centro educativo o semanal en caso de epidemia. También, la Ley sobre Protección de la Salud Pública (1923), estableció en su décimo artículo la obligación de los Jefes de Sanidad, de hacer dos visitas anuales a las escuelas para inspeccionar el estado sanitario de las instalaciones y la condición física e intelectual de los escolares, en caso de ausencia del médico escolar (Ley N 52, 1923).

Tres años después de la promulgación de esa ley, el presidente Ricardo Jiménez decretó un Reglamento de Inspección Médica de las Escuelas, cuya aplicación pasó a estar a cargo de la nueva subsecretaría de Higiene y fue atendida por un director, médicos escolares, asistentes sanitarios escolares y personal docente (Decreto Ejecutivo $\mathrm{N}^{\circ} 2,1926$ ).

La Inspección Médica tuvo por objetivos: la protección de los niños que frecuentaban las escuelas oficiales y privadas contra toda causa de enfermedad, el diagnóstico de enfermedades agudas o crónicas, el tratamiento para los niños pobres y la "observación de los escolares física o intelectualmente anormales".

El médico escolar, debía someter a los niños a un examen individual de su constitución física y mental ${ }^{5}$, dos veces al año, al inicio y al cierre del ciclo escolar. Ese funcionario confeccionaba una tarjeta que debía contener la siguiente información (Decreto Ejecutivo $\mathrm{N}^{\circ}$ 2, 1926): datos antropométricos (medidas de la talla, peso, perímetro torácico); medidas de la acuidad visual y auditiva; examen de la boca, la faringe y la nariz para la constatación respectiva de la caries dental e implantación defectuosa de los dientes; examen del esqueleto en especial para la constatación de los defectos de la columna vertebral (lordosis, sifosis, escoliosis); examen del corazón y de los pulmones para el diagnóstico de

\footnotetext{
${ }^{4}$ El examen del niño fue una práctica que también había propuesto el Dr. Carlos Durán a partir de una ficha individual para llevar un record de los exámenes y condiciones médicas (Velázquez, 2006 p. 27). También el control semanal de los niños, con respecto a peso y con observaciones de la médica Jadwisia Michalski de Picado fueron referidos en las fichas de la Gota de Leche (Botey, 2008)

${ }^{5}$ Esa fue una práctica común sujeta a operaciones de medición escolar, descripción y clasificación según variables que convertían al alumno en objeto de investigación científica al cual podía incidirse en la modificación de su constitución anatómica y mental. (Cordoví, 2012 p. 106)
} 
enfermedades crónicas de esos órganos; antecedentes hereditarios; antecedentes familiares; apreciación del desarrollo mental por el método Binet. ${ }^{6}$ En caso de que algún alumno presentara alguna condición especial, su familia era notificada para que el médico de cabecera lo tratara.

Evidentemente en esa etapa, existió un claro interés, de los médicos, intelectuales y pedagogos, por registrar los aspectos físicos, fisiológicos y mentales de la población escolar, tanto con el propósito de incidir científicamente en la disminución de las tasas de morbilidad y mortalidad infantil, como también, por la necesidad de establecer las bases de una ciudadanía "apta física y mentalmente".

Ese interés continuó un año después de la emisión de ese Reglamento. En 1927, se llevó a cabo el primer censo de población del siglo XX en Costa Rica, un esfuerzo nacional y un registro de cobertura universal, que incorporó la variable "condición mental y física" para la población. El procesamiento de los datos de ese censo, mostró sólo al $0,37 \%$ de la población con alguna de las siguientes condiciones: sordera, ceguera, mudez y demencia. Esto por varias razones, entre éstas, porque la variable "condición mental y física" sólo incluyó esas cuatro condiciones y por ese motivo, el declarante que presentó una discapacidad diferente a las enunciadas no pudo mencionarla; también porque no quiso o no pudo expresarse y además por omisión o sub registro.

Los datos censales del año 1927, corroboraron el carácter excluyente en el acceso a la educación de la población registrada en condición de discapacidad, -por ejemplo la prevalencia en primaria de ese segmento fue de 0.2 (Campos, 2013) -, lo cual evidencia la vigencia de las disposiciones establecidas en la legislación educativa de fines del siglo XIX. Además, se mantuvo el interés de consignar las particularidades físicas, fisiológicas y mentales de los niños en los registros escolares, por lo que la observación, el registro y la exclusión fueron prácticas del sistema educativo vigente entre 1880 y 1940, donde distintos actores de diversas profesiones: médicos, educadores, psicólogos, y funcionarios públicos, fueron los responsables de ejecutarla.

\footnotetext{
${ }^{6}$ Alfred Binet (1857-1911), pedagogo y sicólogo francés, diseñó el test de predicción de rendimiento escolar, que fue la base de los test de inteligencia. Rechazó el método biométrico de Francis Galton que establecía que la inteligencia se medía por atributos físicos.
} 


\subsection{Hacia la Enseñanza Especial}

Los registros escolares y la información censal, dieron cuenta a los encargados de la política pública, de las condiciones físicas y mentales de la población que asistía a las escuelas y de aquella que fue registrada en el censo de 1927.

En los siguientes años, en declaraciones y códigos emitidos se hizo referencia a condiciones de discapacidad en la población menor. Ese fue el caso de la Declaración de los Derechos del Niño Costarricense, presentada por el profesor Luis Felipe González Flores a la directiva del Patronato Nacional de la Infancia el 9 de setiembre de 1930, donde afirmó en uno de los artículos de ese documento que: "el niño tiene derecho a un patrimonio hereditario libre de toda clase de taras que le proporcione el máximo de vitalidad favorable a su desenvolvimiento físico y mental." (Salazar, 2008, p. 59).

Esas palabras retoman el pensamiento vigente en el círculo de médicos, acerca del origen de algunas de las condiciones de discapacidad que tuvo la población, pues desde inicios del siglo XX en Costa Rica, se argumentó que las "taras nocivas" en la población, tenían relación con la endogamia y el alcoholismo (Lachner, 1902, pp. 190-191).

Por otra parte, en el Código de la Infancia emitido en 1932, en el capítulo segundo se hizo referencia a que uno de los medios para procurar la asistencia a menores era "fundar establecimientos para la educación de niños anormales o que padezcan debilidad mental" (Código de la Infancia, 1932), con lo cual se vislumbró esa necesidad desde esa década.

Junto a la práctica de la observación y el registro y de la promulgación de declaraciones y codificaciones emitidas por las autoridades, se sumó una iniciativa impulsada desde la sociedad civil, cuyo propósito fue educar a las personas con discapacidad visual, planteamiento que fue discutido a nivel gubernamental.

Ese fue el proyecto para fundar la "Institución Costarricense de Ciegos", una propuesta presentada al Congreso Constitucional en junio de 1934 por el Ingeniero Francisco de la Paz Cedeño. La Institución sería una entidad que estaría regida por una comisión directiva, dependiente del Poder Ejecutivo y conformada por varios niveles de educación, con una edad de ingreso para el estudiante entre los 6 a los 19 años.

Estaría integrada por una sección de kindergarten para los menores de siete años, un departamento para la enseñanza primaria y otro de enseñanza profesional y artística que podía incluir: un curso completo de masaje para dedicarse a esa profesión en hospitales del país o la enseñanza de la música para dedicarse a ser maestro de canto en las escuelas 
comunes o dar servicios en bailes y fiestas. También se consideró el aprendizaje de oficios como la imprenta, cepillería y escobería.

La institución ejercería como patronato de ciegos y en sus servicios dispondría de: consultorio oftalmológico gratuito, imprenta, biblioteca y gimnasio, asilo para "ciegos incapaces" y casa taller para adultos. También dictaría disposiciones generales o específicas para la prevención de la ceguera.

Se financiaría con fondos del presupuesto nacional, subvenciones de becas asignadas por el Congreso y municipios, además de donaciones particulares. Se ubicaría en la ciudad de San José, con una inversión de sesenta mil colones para construir sus instalaciones. Mientras se resolvía si se aprobaba esa iniciativa, Francisco de la Paz solicitó en su propuesta, que el Ejecutivo subvencionara con tres mil seiscientos colones anuales a la Cruz Roja de San José, para que se ocupara de perfeccionar una escuela para personas con discapacidad visual, que esa institución tenía establecida en esa ciudad.

La propuesta para fundar el Instituto Costarricense de Ciegos, fue acogida por el diputado Jorge Volio Jiménez, pero denegada por los miembros del Congreso bajo los siguientes argumentos: el número de ciegos en el país era reducido; existía un asilo para ancianos donde también estaban los ciegos y la inversión tenía un costo de ф147.840 (La Gaceta, 1934). Fue hasta el año 1943, cuando una propuesta similar fue acogida para el reconocimiento de la personería jurídica del Centro Cultural de Ciegos y de la Escuela Prociegos (Costa Rica, ANCR, 1943). Esa última iniciativa, tuvo lugar cuando ya se había creado la Escuela de Enseñanza Especial.

\subsection{La Escuela de Enseñanza Especial: sus inicios}

\subsubsection{El proyecto}

El preámbulo para la creación de la Escuela de Enseñanza Especial, tuvo lugar al finalizar la década de los años treinta. El Dr. Fernando Quirós Madrigal (1907-1961), graduado como neurólogo y psiquiatra en Bonn, Alemania había creado la sección de Higiene Mental en el Ministerio de Salubridad Pública.

En sus informes del 27 de diciembre de 1938 y del 6 de marzo de 1939, hizo mención a 120 niños examinados por él en las escuelas de San José, que refirió con "anomalías de carácter psico-físico". A ese registro se sumaron 96 individuos de ambos sexos de 8 a 27 años, "diagnosticados y clasificados" en 1939 por el profesor Fernando Centeno Güell (19081993). Además, desde esa fecha, el profesor Centeno Güell inició en su consultorio la 
educación de siete niños con problemas mentales, sordo-mudez y tarta-mudez. Los datos consignados en esos registros, justificaron parte de los argumentos, para proponer la creación de la sección de enseñanza especial del niño bajo la dependencia de la Secretaría de Educación Pública (Costa Rica, ANCR, 1940).

Otra de las razones que se argumentaron en la propuesta, fue que el niño "deficiente psíquico o sensorial" no estaba capacitado para asistir a las escuelas comunes, pues se podía sentir desplazado y eso lo convertiría además de "retrasado mental" en "retrasado pedagógico". También se recurrió a los argumentos del Dr. Gonzalo Rodríguez Lafora, ${ }^{7}$-una autoridad en la materia de esa época-, para señalar que la dificultad intelectual de los "retrasados mentales" hacía que el maestro supeditara la enseñanza de toda la clase al nivel de ese grupo de niños, con perjuicio para los niños de inteligencia "normal". Finalmente se señaló que en Bélgica, España, Italia, Alemania, Estados Unidos, Argentina, Colombia, Chile y México existían escuelas especiales.

Con ese conjunto de criterios, Fernando Centeno Güell, presentó al poder Ejecutivo el 16 de mayo de 1940, un proyecto de ley para la creación de una sección de enseñanza especial del niño, que incluyó un reglamento y un plan pedagógico. El reglamento hizo referencia a los siguientes aspectos, como se indican en la tabla 1.

\footnotetext{
${ }^{7}$ Según consta en el proyecto para crear la sección de enseñanza especial del niño (Costa Rica, ANCR, 1940). El Dr. Rodríguez Lafora era neurólogo y psiquiatra español. Sus investigaciones lo llevaron al descubrimiento de los cuerpos amiláceos en las neuronas de los enfermos de epilepsia mioclónica conocida como enfermedad Lafora. Sus trabajos refieren entre otros asuntos a la psicopatología infantil y además a la promoción de la higiene mental. Uno de sus libros titulado "Los niños mentalmente anormales" (1917) alcanzó una gran divulgación a nivel mundial y por esa publicación fue premiado por la Real Academia de Medicina en su país.
} 
Tabla 1 Reglamento de la Escuela de Enseñanza Especial (1940)

\begin{tabular}{|c|c|}
\hline Admisión & $\begin{array}{l}\text { 1.Niños en edad escolar con "anomalías psíquicas o sensoriales } \\
\text { comprobadas y que sean educables" } \\
\text { 2.Examen médico-pedagógico }\end{array}$ \\
\hline $\begin{array}{l}\text { Ciclo y horario } \\
\text { escolar }\end{array}$ & $\begin{array}{l}\text { 1.Igual al ciclo escolar regular } \\
\text { 2. De 7:30 a.m. a 10:30 a.m. Los lunes miércoles y viernes asistiría el } \\
\text { grupo de niños con "retraso mental". Martes, jueves y sábados los } \\
\text { "disártricos" (sensoriales) } \\
\text { 3.La lección tendría una duración de } 35 \text { minutos con un descanso de } \\
\text { diez minutos entre una lección y otra }\end{array}$ \\
\hline Secciones & $\begin{array}{l}\text { 1.Un grupo de niños con "trastornos auditivos o del lenguaje" } \\
\text { 2.Otro grupo con "trastornos mentales" }\end{array}$ \\
\hline $\begin{array}{l}\text { Personal } \\
\text { funciones }\end{array}$ & $\begin{array}{l}\text { 1.Un director técnico quien tendría a cargo la Dirección; la educación de } \\
\text { los "deficientes sensoriales y de los psíquicos de educabilidad difícil" } \\
\text { 2.Una maestra auxiliar quien tendría bajo su cuidado el grupo de niños } \\
\text { que se le asigne y cooperará con el director y el médico } \\
\text { 3.Un médico psiquiatra, quien llevaría a cabo el examen de ingreso, el } \\
\text { examen periódico y referiría al niño en caso necesario al médico } \\
\text { cabecera de familia o al Departamento Sanitario Escolar } \\
\text { El personal se reuniría una vez al mes para ver la situación de cada } \\
\text { niño }\end{array}$ \\
\hline $\begin{array}{l}\text { Metodología, } \\
\text { procedimiento } \\
\text { s material }\end{array}$ & Se llevaría a cabo de manera individual para cada niño \\
\hline
\end{tabular}

Fuente: Elaboración propia a partir de: Costa Rica, ANCR, \# 004014, 16 de mayo de 1940

Debido a que el reglamento establecía dos secciones, el plan pedagógico se organizó de esa manera: la sección de "deficientes psíquicos" y la de "deficientes sensoriales" con diferentes niveles o etapas, tal y como se observa de seguido en la tabla 2.

Tabla 2 Plan Pedagógico de la Escuela de Enseñanza Especial (1940)

\begin{tabular}{|c|c|c|c|c|}
\hline \multicolumn{2}{|c|}{ "Deficientes psíquicos" } & \multicolumn{3}{|c|}{ "Deficientes sensoriales" } \\
\hline \multicolumn{2}{|l|}{ Niveles } & \multicolumn{3}{|l|}{ Etapas } \\
\hline Preparatorio & Superior & Primera & Segunda & Tercera \\
\hline $\begin{array}{l}\text { 1.Hábitos de } \\
\text { limpieza personal y } \\
\text { de buen } \\
\text { comportamiento } \\
\text { 2.Ejercicios de } \\
\text { movilidad tónica } \\
\text { para hipo activos y } \\
\text { de inmovilidad para } \\
\text { hiperactivos } \\
\text { 3.Ejercicios físicos, } \\
\text { de orientación, de } \\
\text { vida práctica, } \\
\text { actividad de los } \\
\text { sentidos (ejercicios } \\
\text { montesorianos): } \\
\text { vista, oído, gusto, }\end{array}$ & $\begin{array}{l}\text { La enseñanza se } \\
\text { adaptará a las } \\
\text { condiciones } \\
\text { mentales de cada } \\
\text { alumno, tomando } \\
\text { de guía la } \\
\text { diferentes } \\
\text { asignaturas de los } \\
\text { programas de } \\
\text { educación } \\
\text { primaria }\end{array}$ & $\begin{array}{l}\text { Ejercicios } \\
\text { preliminares: } \\
\text { comprende } \\
\text { educación } \\
\text { muscular y } \\
\text { sensorial }\end{array}$ & $\begin{array}{l}\text { "Desmutización": } \\
\text { Para "sordomudos } \\
\text { con restos } \\
\text { auditivos": } \\
\text { vocalización, } \\
\text { gimnasia linguo- } \\
\text { dento-labial, } \\
\text { lectura labial } \\
\text { sintética, ejercicios } \\
\text { de respiración } \\
\text { fonéticos } \\
\text { articulatorios. } \\
\text { Formación de } \\
\text { vocales, } \\
\text { consonantes, } \\
\text { sílabas inversas, }\end{array}$ & $\begin{array}{l}\text { Instrucción: } \\
\text { Determinada } \\
\text { por el grado de } \\
\text { desarrollo } \\
\text { intelectual del } \\
\text { niño }\end{array}$ \\
\hline
\end{tabular}




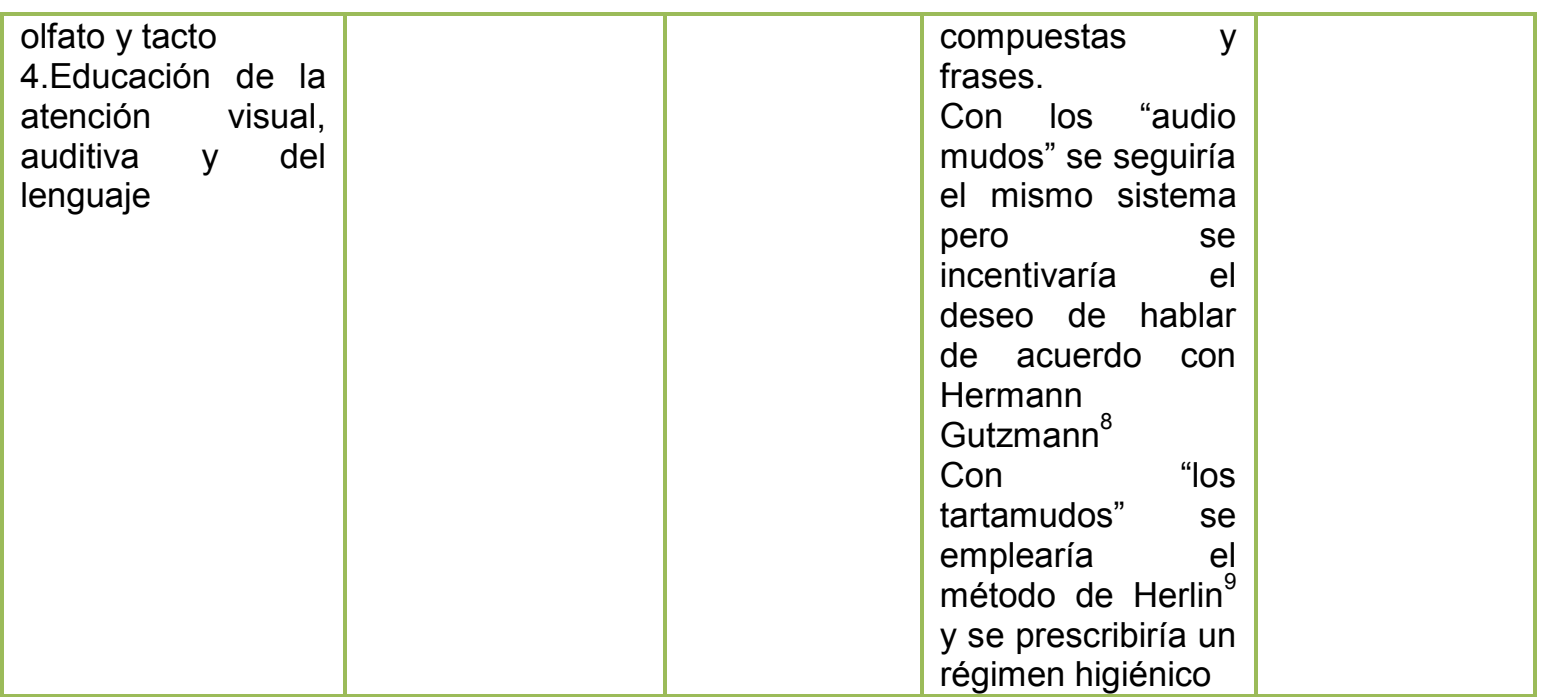

Fuente: Elaboración propia a partir de: Costa Rica, ANCR \# 004014, 16 de mayo de 1940

Con respecto al grupo de los "deficientes psíquicos", se afirmó que la finalidad primordial del "tratamiento médico-pedagógico era educar y desarrollar las capacidades psíquicas del niño con el fin de adaptarlo y hacerlo útil socialmente". En el caso de los niños con tartamudez, se indicó que se usaría el "tratamiento moral tendiente a despertar en ellos la confianza y la voluntad necesarias para no desmayar hasta obtener la desaparición del defecto" (Costa Rica, ANCR, 1940, p. 6).

Los argumentos planteados sobre la necesidad de fundar una escuela de enseñanza especial, se complementaron con la elaboración del reglamento y el plan pedagógico para diseñar la propuesta completa al Poder Ejecutivo. La persistencia del profesor Centeno Güell y su amistad con el Presidente de la República Dr. Rafael Calderón Guardia, con su ministro de Educación Pública Luis Demetrio Tinoco y con el jefe técnico de educación José Fabio Garnier, llevaron a la emisión del Decreto Ejecutivo № 10 con fecha del 23 de julio de 1940 para la creación de la Escuela.

\subsubsection{Legislación, organización e infraestructura}

La Escuela de Enseñanza Especial, surgió en un contexto en que se venía haciendo referencia a la situación de la población escolar en condición de discapacidad y a la necesidad del acceso a la educación de ese grupo de niños. Gracias a la iniciativa de

\footnotetext{
${ }^{8}$ Hermann Gutzmann, médico alemán que estudió el habla y la voz. Fundó la foniatría en Berlín

${ }^{9}$ A. Herlin en 1926 elaboró un método para las personas que tenían condición de mudez y que tuvo gran difusión en Europa
} 
profesionales, padres de familia y con apoyo del Poder Ejecutivo finalmente se decretó su creación.

En el considerando del decreto $\mathrm{N}^{\circ} 10$, se retomó lo planteado en la propuesta del proyecto. Se indicó que la educación del grupo de niños en esa condición, no podía desarrollarse en las escuelas comunes, por el perjuicio que corrían los programas ordinarios. A la vez se hizo referencia, a que la condición de esos niños no permitía que se sometieran a los horarios, normas de trabajo y reglamentos de la escuela común. Por último se afirmó: "El Estado no debe permanecer indiferente a la suerte de estos niños, sino más bien procurar su mejoramiento de acuerdo con los recursos que indica la ciencia médica y la psicología" (Decreto Ejecutivo $\mathrm{N}^{\circ} 10,1940$, p. 338).

Además, en la ley se indicó que la enseñanza especial era para la atención de niños con "retraso mental y con trastorno auditivo o vocal" y el propósito de la institución era educarlos y desarrollar sus facultades para hacerlos útiles en la vida social. Su ingreso a la institución, estaría sujeto al dictamen del médico jefe del Departamento Sanitario preescolar y escolar. Los sueldos de los funcionarios de la escuela, se cargaron al presupuesto del personal docente de la provincia de San José y el decreto entró en vigencia a partir del primero de agosto de 1940. El 14 de noviembre de 1941, el presidente Calderón promulgó el decreto $\mathrm{N}^{\circ} 26$ que estableció la Dirección Técnica de Enseñanza Especial, debido al interés de formar otras escuelas en el futuro (Decreto ejecutivo $\mathrm{N}^{\circ} 26,1941$ ).

La Escuela de Enseñanza Especial tuvo como finalidad "cuidar el aspecto mental y físico del niño deficiente, mediante una instrucción adecuada o desarrollando sus capacidades para el trabajo manual", bajo el principio de gratuidad de la enseñanza y para niños de ambos sexos en edades de 7 a 14 años (Centeno, 1941, p.4).

Inicialmente el profesor Fernando Centeno Güell, la maestra Flora Bourillón y los doctores Quirós Madrigal y González Murillo del Hospital Nacional Psiquiátrico, fueron el personal que llevó a cabo las primeras tareas con ocho niños, en una oficina al costado oeste del parque Morazán en San José. La profesora Gladys Odio -quien presentó su tesis en la Escuela Normal sobre el área de retardo mental-se incorporó a la escuela seis meses después (Benavides, s.f.).

La institución se localizó más tarde en una casa alquilada en el barrio González Lahmann en San José, frente a la casa de Matute Gómez con buenas condiciones higiénicas, bien decorada para el propósito que fue destinada y con un mobiliario de 
estantes, sillas y mesas amplias (Costa Rica, ANCR, 1940). En 1944 se trasladó a Guadalupe de Goicoechea donde se encuentra actualmente.

Para trabajar con los niños, la escuela requirió de una pizarra de clase, tres mesitas, 18 sillas y un espejo con su caballete para ejercicios de articulación, mobiliario que tuvo un costo de $\phi 240$. Luego contó con material técnico importado, pues se trajo para el uso de los estudiantes de la escuela, un sistema de aparatos electrofonoides para los niños con sordomudez con un valor de $\$ 340$ (Costa Rica, ANCR, 1940 y 1941).

En la institución se siguieron tendencias en el aprendizaje, provenientes de escuelas españolas, belgas, alemanas y estadounidenses. Se trabajó con terapia ocupacional, se emplearon aparatos electrofónicos y procedimientos para la educación de la vista, el oído y el tacto ${ }^{10}$. Otro tipo de actividades desarrolladas por el personal de la escuela fueron: visitas a varias instituciones de San José, Limón y Alajuela, tanto a escuelas, como a los hospicios y al asilo Chapui. También, se llevó a cabo la apertura de una sección para niños "retrasados" en la escuela de Atenas y la divulgación de los métodos y prácticas de la Escuela de Enseñanza Especial.

Su ley constitutiva estableció de interés público la educación de los niños con retraso mental, trastorno auditivo, de la vista, vocal o impedimento físico que lo limitara para recibir lecciones en la escuela común. El plan educacional contempló internados, clases y talleres de aprendizaje de oficios y el financiamiento dependió de rentas generadas por impuestos y por el aporte de ingresos ordinarios asignados por el Poder Ejecutivo para ser administradas por una junta (Ley N61, 1944).

\subsection{El personal, los alumnos y sus familias}

Un año después de iniciar labores, su personal estuvo integrado por un director, un médico psiquiatra del Departamento de Higiene Mental, una enfermera y cuatro profesoras: Flora Bourillón, Gladys Odio, Dinorah de Navarro y Marina de González (Centeno, 1941, p. 14). Las maestras eran graduadas en la Escuela Normal y además se fueron a preparar al Instituto Nacional de Pedagogía Terapéutica de Madrid con la profesora María Soriano Llorente. Además, como parte de los servicios profesionales que ofreció la escuela, a los alumnos se les efectuaban exámenes de laboratorio y se les establecía un régimen de higiene y dieta.

\footnotetext{
10 Autores citados por Fernando Centeno fueron: Rouma, Herlin, Decroly, Montessori, Ponce de León, Descoeudres y Lafora
} 
También el reglamento fijó requerimientos para los médicos que trabajaban para la escuela, tales como estar incorporados al Colegio de Médicos y Cirujanos y tener la especialidad en Higiene Mental, mientras que el personal administrativo fue seleccionado por el director de la institución.

El personal docente se eligió por ternas con varios requisitos: título de maestro en educación primaria, aprobación de cursos establecidos en el reglamento y pruebas de idoneidad frente al director de la institución. El ingreso del alumno a la escuela contó con el dictamen del director y de un médico especialista.

Con respecto a los estudiantes de la Escuela de Enseñanza Especial, la información consignada en 147 expedientes encontrados en la institución ${ }^{11}$, permitieron referir algunas características del alumnado. Las fechas extremas de ese conjunto de documentos son 1942 y 1980, sin embargo, no hay una secuencia cronológica completa, esto debido al deterioro, pérdida o problemas de ubicación e infraestructura idónea.

De los primeros años de funcionamiento de la escuela, sólo se encontró un expediente que data del año 1942, los demás corresponden predominantemente a la década de los años sesenta, no obstante, a pesar de que la información de esos expedientes trasciende el límite temporal en el que se inscribe este trabajo, resulta interesante consignar los resultados ofrecidos por esa fuente, como un intento de ilustración y aproximación a las características de los niños y sus familias y además porque pone de relieve la importancia del expediente del estudiante.

El único expediente de los años iniciales de labor en la institución, registró a un niño que ingresó en 1942, ahí se consignó solamente que tenía seis años de edad, había nacido en San José y residía en Barrio Amón. Su padre era comerciante y el motivo por el cual fue llevado a la institución, fue la dificultad en el aprendizaje.

Con respecto a la información disponible en esas 147 carpetas de documentos, se constató que un $6 \%$ de esos expedientes, correspondieron a estudiantes que ingresaron a la institución durante las dos primeras décadas de funcionamiento de la escuela, un 50\% pertenecieron a expedientes de alumnos que se inscribieron en los años sesenta y un $44 \%$ correspondió a quienes fueron matriculados en el decenio siguiente.

Acerca del lugar de nacimiento de esos niños, los datos consignados en esos expedientes mostraron que el $75 \%$ de los alumnos nacieron en la provincia de San José. El

\footnotetext{
11 A solicitud nuestra y gracias al permiso otorgado por la directora de la Escuela Fernando Centeno Güell, Licenciada Zarelly Sibaja, se tuvo acceso a 147 expedientes de estudiantes de la institución que se encontraban en una bodega.
} 
otro $25 \%$ correspondió a las provincias de Cartago, Heredia, Alajuela y Limón. No se dispuso de expedientes de alumnos nacidos en Puntarenas o Guanacaste.

En el momento en que ingresaron a la institución, los niños de las familias residentes en los barrios josefinos como Aranjuez, Barrio Cuba o La Merced y en cantones cercanos a la capital como Goicoechea, Alajuelita y Desamparados, fueron los que predominaron en el conjunto de los escolares inscritos. El estudio de los expedientes mostró que la institución también tuvo niños cuyas familias vivían en las demás provincias, excepto en Limón y Guanacaste, pues no se contó en esa fuente con información de personas residentes en esos lugares.

En ese conjunto de casos disponibles, se constató que los niños josefinos primordialmente, fueron los que tuvieron mayores posibilidades de inscribirse y asistir a la Escuela de Enseñanza Especial.

Por otra parte, los datos disponibles refieren que un $2 \%$ de los alumnos nacieron en las décadas de 1930 y 1940, un 7\% en el primer quinquenio de los años cincuenta y un $36 \%$ en el siguiente lustro. A los primeros cinco años del decenio de los años sesenta, correspondió un $34 \%$ de nacimientos y al cierre de esa década se registró un $18 \%$. Hubo un $2 \%$ sin ese dato. Los rangos de edad de ese grupo de estudiantes de la Escuela de Enseñanza Especial en el momento del ingreso a la institución se aprecian en el gráfico 1.

Gráfico 1

Escuela de Enseñanza Especial: población escolar por grupos de edad (\%)

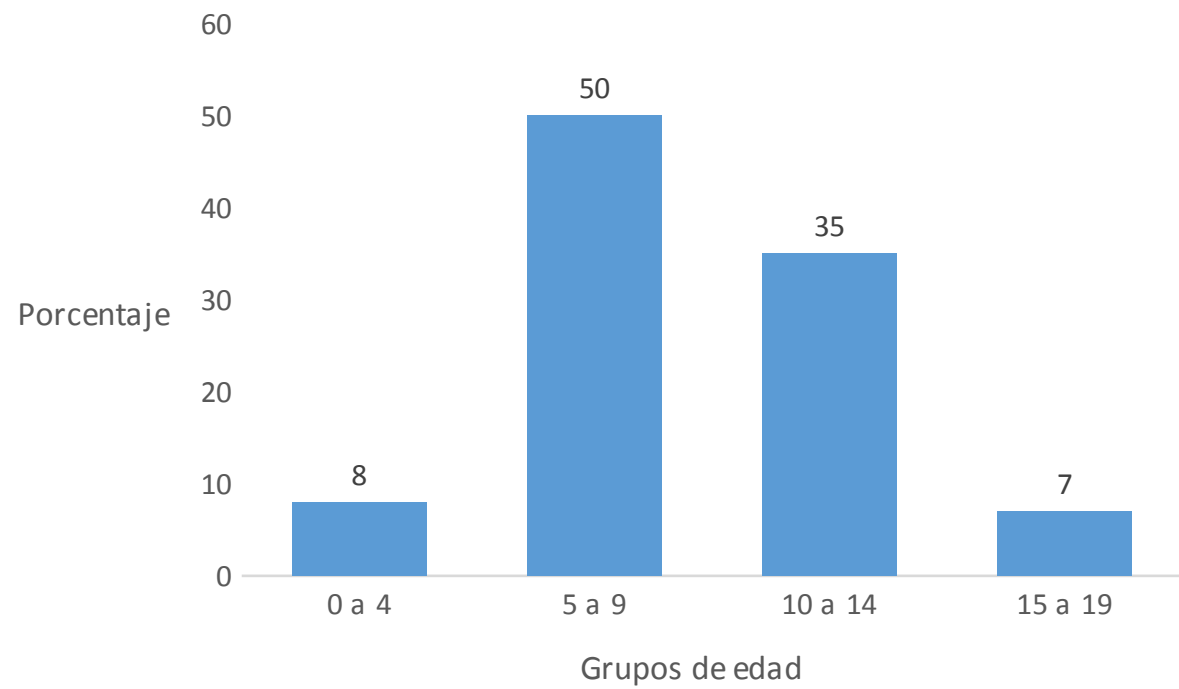

Elaboración propia a partir de expedientes de estudiantes disponibles (1942-1980) 
Como se puede apreciar en el gráfico anterior, de acuerdo con la información disponible en esos expedientes, la mitad de los estudiantes ingresaron a la institución después de cumplir cinco años de edad. En el cuadro 1 se aprecia el quinquenio en que ingresaron a la escuela y la distribución por grupos de edad, donde los datos disponibles parecen confirmar que independientemente del quinquenio en que ingresaron esos estudiantes a la escuela, la tónica fue la matrícula entre los 5 y 9 años de edad, seguidos de quienes ingresaron entre los 10 y 14 años.

Cuadro 1 Estudiantes de la Escuela de Enseñanza Especial por quinquenio de ingreso a la institución y grupos de edad (Números absolutos)

\begin{tabular}{|l|c|c|c|c|}
\hline \multirow{2}{*}{$\begin{array}{l}\text { Período de } \\
\text { ingreso }\end{array}$} & \multicolumn{4}{|l|}{ Grupos de edad } \\
\cline { 2 - 5 } & 0 a 4 años & 5 a 9 años & 10 a 14 años & 15 a 19 años \\
\hline 1942 & & 1 & & \\
\hline $1955-1959$ & 2 & 1 & & \\
\hline $1960-1964$ & 3 & 10 & 2 & \\
\hline $1965-1969$ & 7 & 34 & 18 & 5 \\
\hline $1970-1974$ & 1 & 18 & 24 & 3 \\
\hline $1975-1979$ & & 7 & 6 & \\
\hline 1980 & & 1 & & 9 \\
\hline ND & 3 & & & 50 \\
\hline Total & 16 & 72 & & \\
\hline
\end{tabular}

Elaboración propia a partir de expedientes de estudiantes disponibles (1942-1980)

Vale la pena señalar, que antes de $1970^{12}$ la enseñanza preescolar no era un requisito de ingreso obligatorio para los niños, sin embargo, dentro de los expedientes consignados se encuentra un grupo de estudiantes en edad preescolar en la Escuela de Enseñanza Especial como se aprecia en el cuadro anterior, lo que devela que existió interés por dar atención en forma temprana.

Otro de los aspectos de interés, dentro de las características de la población estudiantil de esa escuela, fueron las razones por las cuales ingresaron los niños a la institución. En el cuadro 2 se observa los diferentes tipos de discapacidades que fueron el motivo por el cual los escolares fueron matriculados en ese centro y la distribución por grupos de edad de acuerdo con la información de los expedientes disponibles.

\footnotetext{
12 Aunque en el país funcionaron maternales y escuelas preescolares de carácter privado y católico como el Kínder Moderno y la Escuela Alemana y por Decreto Ejecutivo \# 14 del 7 de julio de 1941 se estableció el Departamento Sanitario Preescolar y de Educación Sanitaria fue hasta el 18 de julio de 1979 por Decreto Ejecutivo \#10285 que se creó y reglamentó el Departamento de Educación Preescolar. En: Sistema Costarricense de Información Jurídica. http://www.pgr.go.cr/SCIJ/
} 
Cuadro 2 Estudiantes de la Escuela de Enseñanza Especial por tipo de discapacidad que motivó el ingreso a la institución y por grupos de edad

(Números absolutos)

\begin{tabular}{|c|c|c|c|c|}
\hline \multirow[t]{2}{*}{ Tipo de discapacidad } & \multicolumn{4}{|c|}{ Grupo de edad } \\
\hline & $\begin{array}{ll}0 & \text { a } \\
\text { años }\end{array}$ & $\begin{array}{l}5 \quad \text { a } 9 \\
\text { años }\end{array}$ & $\begin{array}{l}10 \text { a } 14 \\
\text { años }\end{array}$ & $\begin{array}{l}15 \text { a } 19 \\
\text { años }\end{array}$ \\
\hline Retraso mental & & 8 & 5 & 4 \\
\hline Retardo Mental & & 20 & 19 & \\
\hline $\begin{array}{ll}\text { Dificultad } & \text { para } \\
\text { aprender } & \end{array}$ & & 21 & 26 & 3 \\
\hline Sordera & 6 & 8 & 1 & 2 \\
\hline $\begin{array}{l}\text { Mudez y problemas } \\
\text { del lenguaje }\end{array}$ & 1 & 5 & 1 & \\
\hline Sordo-mudez & 4 & 3 & & \\
\hline Problemas de ojos & & 2 & & \\
\hline Hiperactividad & & 1 & & \\
\hline Epilepsia & & 1 & & \\
\hline ND & 3 & 1 & & \\
\hline
\end{tabular}

Elaboración propia a partir de expedientes de estudiantes disponibles (1942-1980)

La distribución porcentual de los diferentes tipos de discapacidad, se observa en el gráfico 2 y mostró en primer término las discapacidades mentales (40\%) como la razón que llevó al ingreso del niño en la institución. La segunda razón fue la dificultad para aprender $(36 \%)$ y las siguientes causas de la matrícula en la escuela se relacionaron con discapacidades sensoriales: sordera, mudez y problemas visuales (24\%).

\section{Gráfico 2}

Escuela de Enseñanza Especial: Condición de ingreso de la población escolar (\%)

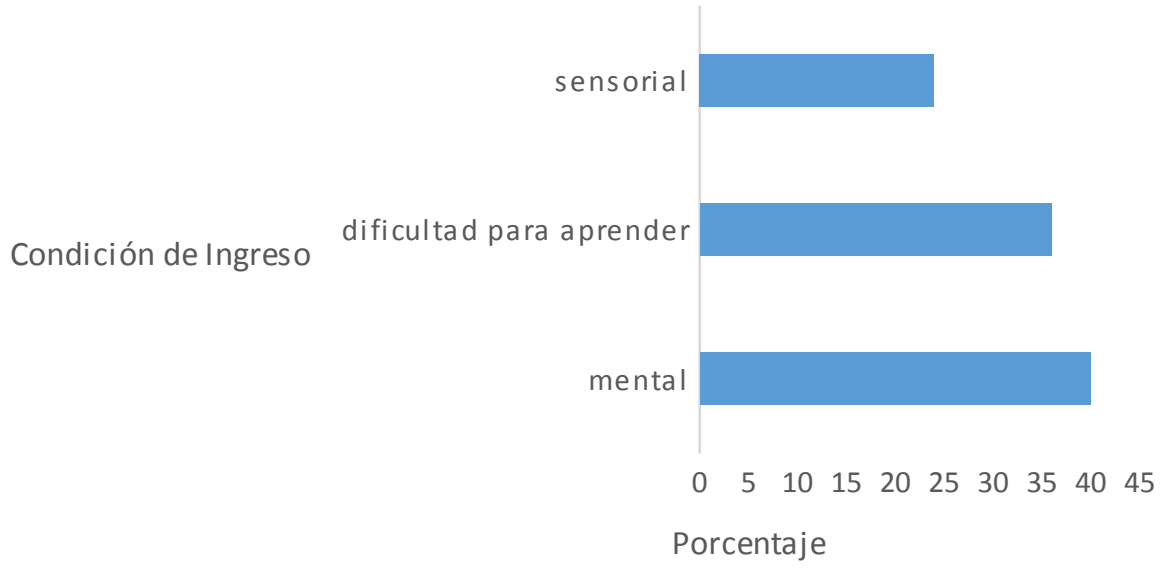

Elaboración propia a partir de expedientes de estudiantes disponibles (1942-1980) 
Al comparar esos datos de la población escolar, con los resultados correspondientes a los censos de población del año 1927 y del año 2000, se constata que las discapacidades sensoriales y mentales han sido connotadas en la sociedad costarricense.

En el censo del año 1927, -como se indicó en las páginas precedentes-, las cuatro discapacidades que se registraron fueron: ceguera, sordera, mudez y demencia. En esa fecha censal, los niños en edades de 5 a 14 años que fueron registrados en esa fuente, presentaron la siguiente distribución porcentual: las discapacidades sensoriales fueron representadas con un $81 \%$ (sordera $62 \%$, ceguera $20 \%$ y mudez $18 \%$ ). En el caso de la discapacidad mental se registró un $19 \%$

El registro del año 2000, presentó un panorama más diverso, con respecto a las discapacidades declaradas por la población en el año censal de 1927. En el 2000 las discapacidades registradas fueron: ceguera parcial o total, sordera parcial o total, retardo mental, parálisis y amputación, trastorno mental y "otras" que agrupó: enfermedad pulmonar obstructiva, fibrosis quística, labio leporino, mudez y epilepsia.

La distribución porcentual en el año 2000, en el grupo de edad de 5 a 14 años, mostró en primer término la ceguera (26\%) como causa de discapacidad. La categoría "otras" ocupó el segundo lugar en esa distribución (24\%). El retardo que agrupó a los niños con síndrome de Down y todos los grados de retardo mental conocidos, representó un $23 \%$. La parálisis y la amputación con un 11\%, resultó ser la cuarta causa de discapacidad, que reunió a niños con parálisis cerebral, dificultad física por poliomielitis, artritis severa, malformación congénita, pacientes con mal de Parkinson y con amputación. La sordera dejó de ser tan connotada en año 2000 (10\%) como lo fue en 1927. En el caso del trastorno mental (6\%) el censo incluyó: sicosis, esquizofrenia, neurosis, demencias y depresión permanente (INEC, 2000).

La confrontación de la información censal con el registro de los expedientes disponibles de los estudiantes de la Escuela de Enseñanza Especial, corrobora la importancia de las discapacidades referidas en la población escolar.

Otro de los aspectos interesantes de dilucidar acerca de la población estudiantil de la Escuela de Enseñanza Especial, fueron las discapacidades presentes en la familia, que se consignaron en los expedientes encontrados como antecedentes familiares. Además, en ese historial se hizo referencia a la situación de salud de la madre, circunstancia que se consideró incidió en la condición de discapacidad de los niños. 
Aunque en la mitad de los expedientes no se registraron esos datos, en el otro $50 \%$ los declarantes establecieron relaciones con parientes desde el primero hasta el cuarto grado de consanguinidad como se aprecia en el gráfico 3.

Gráfico 3

Escuela de Enseñanza Especial: Situación de salud y de discapacidad de los parientes de la población escolar referidos como antecedentes de familia que incidieron en la condición del niño

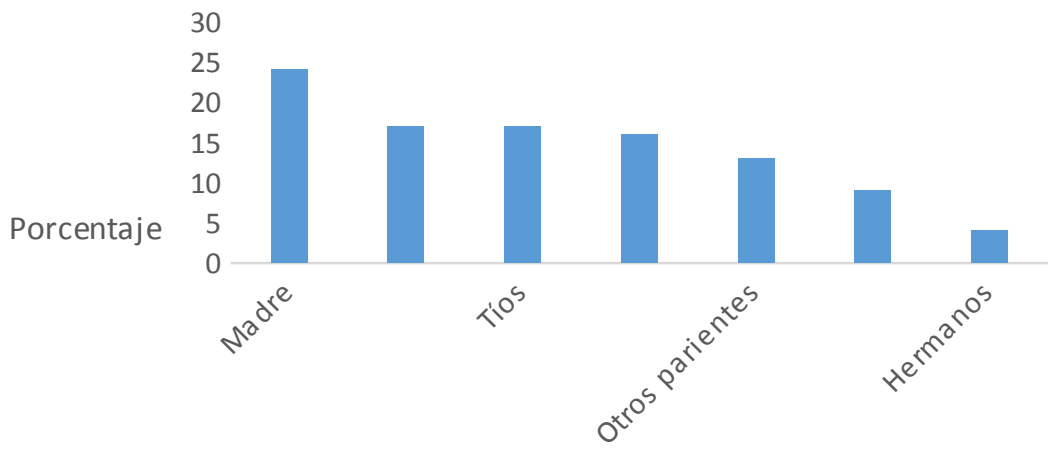

Parentesco

Elaboración propia a partir de expedientes de estudiantes disponibles (1942-1980)

La madre registró con el mayor porcentaje (24\%). En la mitad de esos casos, la situación de salud de la progenitora, se relacionó con padecimientos durante el embarazo como fueron: rubéola, sarampión y anemia, circunstancias consignadas como incidencia en la condición de discapacidad de los niños. En la otra mitad de los casos, se hizo referencia a trastornos en el sistema nervioso y mental, que presentó la madre, como una condición hereditaria para su hijo.

Los abuelos maternos y paternos fueron citados con condiciones como las siguientes: epilepsia, trastorno mental y sordera. También se hizo mención a tuberculosis y cáncer entre otras, como razones con algún grado de incidencia en la condición de los niños. Primos, tíos y otros parientes, fueron mencionados con las siguientes situaciones: retardo y retraso mental, demencia, sordera, mudez, alcoholismo y ceguera.

La distribución porcentual de la condición de salud y de discapacidad presente en los familiares de los estudiantes de la Escuela de Enseñanza Especial registrada en los expedientes se observan en el cuadro 3. 
Cuadro 3 Escuela de Enseñanza Especial: Distribución porcentual de la condición de salud y discapacidad en los parientes de la población escolar

\begin{tabular}{|l|l|}
\hline Condición & $\%$ \\
\hline Discapacidad mental & 23 \\
\hline Enfermedades & 21 \\
\hline Discapacidad sensorial & 6 \\
\hline ND & 50 \\
\hline
\end{tabular}

Elaboración propia a partir de expedientes de estudiantes disponibles (1942-1980)

Con respecto a las familias de los estudiantes de la Escuela de Enseñanza Especial, los expedientes ofrecen datos acerca del número de hijos en el hogar, destacando con un $23 \%$ las familias que tuvieron cinco niños, como se aprecia en el cuadro 4.

Cuadro 4 Escuela de Enseñanza Especial: Distribución porcentual del número de hijos presentes en el hogar de la población escolar

\begin{tabular}{|c|c|}
\hline Número de hijos en el hogar & \% de hogares \\
\hline 1 & 3 \\
\hline 2 & 14 \\
\hline 3 & 7 \\
\hline 4 & 12 \\
\hline 5 & 23 \\
\hline 6 & 13 \\
\hline 7 & 6 \\
\hline 8 & 8 \\
\hline 10 y más & 4 \\
\hline
\end{tabular}

Elaboración propia a partir de expedientes de estudiantes disponibles (1942-1980

Los hogares de los niños de la Escuela de Enseñanza Especial, estuvieron conformados por diferente número de hijos, desde el hogar con hijo único, hasta aquel en el que el niño compartió con muchos hermanos. Vale la pena señalar, que en el país hasta la década de 1960 predominaron las familias con más de siete hijos, después de 1965 se redujo a 6,5 ese número y para 1975 ya había bajado a cuatro hijos por familia (Rosero, 1985, p.193), por lo que existe una correspondencia entre esos datos y los consignados en los expedientes disponibles de los estudiantes de la Escuela de Enseñanza Especial.

Otra correspondencia se observó al correlacionar a las madres de esos niños de la Escuela de Enseñanza Especial que trabajaron fuera del hogar en ocupaciones mejor calificadas, tales como maestra, enfermera o farmacéutica, con respecto al número de hijos, lo que dio como resultado un número de hijos inferior a siete. Esa misma condición fue observada para el país, pues en los grupos de mujeres incorporadas al trabajo y con más años de educación, fue menor el número de hijos (Rosero, Gómez y Rodríguez, s.f.). 
Por otra parte, al indagar en la situación laboral y las ocupaciones de las progenitoras se tuvieron los siguientes hallazgos en los expedientes disponibles. El 80\% de esas madres se dedicaron a oficios domésticos en su hogar y un $8 \%$ no consignó ese dato. En el grupo de las que laboraron fuera de su casa, se encontró a un 6\% en ocupaciones como maestras, también en enfermería y farmacia. En el sector artesanal y manufacturero (2\%) se encontraron costureras y trabajadoras en fábrica y en el sector servicios estaban incorporadas otro $2 \%$ de las mamás de esos niños. Un $1 \%$ se desempeñaron en oficios agrícolas y ese mismo porcentaje se consignó como estudiante.

Respecto a la situación laboral de los padres de esos niños, se registraron diversas ocupaciones, profesiones y oficios. También hubo un $17 \%$ de casos donde no se declaró el oficio del padre y un 3\% sin trabajo. El gráfico \# 4 muestra el detalle.

Gráfico 4

Escuela de Enseñanza Especial: Situación laboral de los padres de familia de los escolares

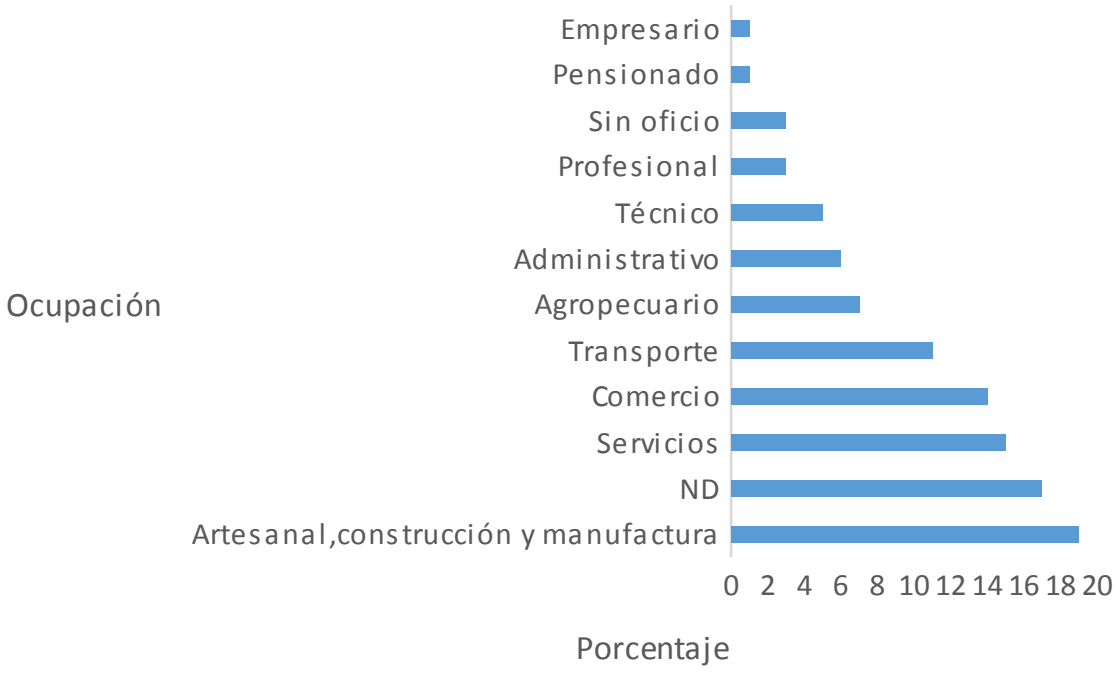

Elaboración propia a partir de expedientes de estudiantes disponibles (1942-1980)

Los papás que laboraron en el sector artesanal, construcción y manufactura representaron un $19 \%$ y estaban dedicados a la actividad de albañilería, carpintería, ebanistería y algunos trabajaron como ayudantes de construcción. En los sectores de servicios y comercio, se ubicó un porcentaje significativo de los papás de esos niños, 15\% y 14\% respectivamente, así como en el área del transporte (11\%). En el sector agropecuario laboraron sólo un $7 \%$ de esos padres de familia, lo que mostró que la mayor parte de ellos estaban empleados en oficios y profesiones urbanas. 
En la Escuela de Enseñanza Especial, no sólo estuvo un grupo de niños que requirió de la atención especial de sus maestros, esos niños formaron parte de hogares de diverso tamaño, composición, ubicación geográfica y social. Por otro lado, la información parcial o la ausencia de datos referida al padre que se encontró en algunos de esos expedientes, podrían sugerir que en algunos casos hubo familias incompletas, es decir, el padre estuvo ausente.

Otra característica de los hogares de esos niños, fue la diversidad de sectores sociales presentes. El hijo del comerciante, del ingeniero, del albañil, de la farmacéutica y de la costurera acudieron a ese centro, todos estudiaron en la misma escuela. Por último, fue significativo el predominio urbano y particularmente josefino de los hogares de los alumnos de la Escuela de Enseñanza Especial.

\section{Conclusiones}

Los ejes de la política seguida en materia de salud y educación para la población en condición de discapacidad en el lapso 1880-1940 fueron la exclusión y la segregación.

En ese contexto, la observación y el registro fueron mecanismos para clasificar a la población escolar de acuerdo a sus condiciones físicas, fisiológicas y mentales utilizando criterios científicos de la época tales como talla, peso, medidas, agudeza visual y auditiva, con el objetivo de incidir en las tasas de morbilidad y mortalidad y a la vez establecer las bases de una ciudadanía "apta física y mentalmente". Esas taxonomías fueron fruto del método científico y de los discursos biologistas y sociologistas dominantes en esa época. La pretensión era explicar la condición del niño y remediarla.

La puesta en marcha de esos mecanismos fue viable a partir de: la asociación entre las carteras de educación y salud y la institucionalización de ese vínculo con el surgimiento del Departamento Sanitario Escolar en 1914; la creación de la Subsecretaría de Higiene y Salud Pública (1922) y la Ley sobre Protección de la Salud Pública emitida en 1923, instancias y legislación que incentivaron la observación y el examen individual del niño. Además, con el Reglamento de Inspección Médica de las Escuelas (1926), fueron definidos los criterios para registrar las condiciones físicas, fisiológicas y mentales de los escolares.

Entre 1880 y 1940, distintos actores de diversas profesiones como lo fueron médicos, educadores, sicopedagogos, todos miembros de los círculos de intelectuales de la época y la mayor parte de las veces desempeñando tareas como funcionarios públicos, fueron los responsables de poner en marcha esas políticas, esos mecanismos y esos criterios. 
En el Código de la Infancia emitido en 1932, se estableció por primera vez la necesidad de fundar establecimientos para la educación de los niños con discapacidades, con lo cual se planteó esa posibilidad desde esa década.

Dos de las primeras propuestas para fundar establecimientos para la educación de la población con discapacidades, surgieron en el país en la década de los años treinta desde órganos como la Cruz Roja de San José y a partir de una iniciativa individual elevada al Congreso Constitucional. Esa constatación indica que además de los órganos estatales, las organizaciones de la sociedad civil plantearon sus propuestas para atender demandas de grupos específicos de la población con discapacidad.

El proyecto y la puesta en marcha de la Escuela de Enseñanza Especial partieron de la asociación entre medicina y pedagogía mediante la Pedagogía Terapéutica una disciplina en la cual se formó el personal de ese centro de estudios.

El expediente del estudiante constituye una fuente muy valiosa de información, que además de constatar la atención que recibió esa población en la institución, permitió acercarse a distintas características de los estudiantes y de sus familias, que en un universo secuencial ofrecería una gran riqueza para un conocimiento más vasto de la situación de vida de las personas en condición de discapacidad en el país.

El contexto socio histórico es esencial para comprender las características en que surgió la Enseñanza Especial en Costa Rica. En la etapa en que fue fundada la Escuela de Enseñanza Especial (1940), estuvo vigente en el país un modelo de atención para la población en condición de discapacidad, con un enfoque basado en deficiencias, que enfatizó en un concepto de salud que partió del individuo, de la normalidad de sus estructuras, de sus funciones fisiológicas y mentales y de la ausencia de enfermedad.

En ese modelo de atención, -el bio-médico-, la deficiencia se observó como síntoma de enfermedad, razón por lo cual al sujeto con discapacidad, se le definió como un individuo enfermo.

Una de las respuestas al poner en marcha ese modelo de atención respaldado por la comunidad de médicos, círculo de intelectuales y políticos del país, fue la segregación, ese fue el caso de las personas con discapacidades mentales ingresadas en el Asilo Chapuí (1890), una práctica común en otras latitudes desde épocas más tempranas.

El grupo de intelectuales, profesionales y políticos costarricenses, que respaldó ese modelo de atención, mantuvo vínculos con círculos afines en el extranjero, muchas veces asociados con los estudios superiores que llevaron a cabo fuera del país, lo que les permitió 
tener acceso a teorías y prácticas en distintas disciplinas, influencias que después se definieron en discurso, práctica y política pública en Costa Rica.

La Enseñanza Especial en Costa Rica, nació en ese contexto, estando vigente un concepto y modelo de atención para las personas en condición de discapacidad basado en la deficiencia y bajo la influencia de teorías y prácticas que circularon en el extranjero, donde profesionales de disciplinas del área de salud, personal pedagógico y asistencial tuvieron el mayor protagonismo.

La asociación entre las disciplinas del área de salud y de educación, hizo viable el surgimiento de la Enseñanza Especial. El conocimiento etiológico de algunas deficiencias y las posibilidades de educabilidad de las personas con discapacidades sensoriales y mentales posibilitaron ese desarrollo en distintos países. Costa Rica no fue la excepción, la concurrencia de médicos, siquiatras, sicólogos, pedagogos y especialistas en Pedagogía Terapéutica, dieron fundamento al surgimiento de la Escuela de Enseñanza Especial en 1940.

\section{Referencias}

Benavides, Zaida. (s.f.). Ecos de la Historia Centro Nacional de Educación Especial Fernando Centeno Güell. San José: Ministerio de Educación Pública. Recuperado de http://www.google.com/url?sa=t\&rct=i\&q=\&esrc=s\&source=web\&cd=1\&ved=0CB8QFjAA\&u $\mathrm{rl}=\mathrm{http} \% 3 \mathrm{~A} \% 2 \mathrm{~F} \% 2 \mathrm{Ffundamentos}$ delaeducacionespecial.wikispaces.com\%2Ffile\%2Fview\% 2FEcos\%2Bde\%2Bla\%2Bhistoria\%2B\%2528sin\%2Bim\%25C3\%25A1genes\%2529.doc\&ei =HjF-VP 6FYmPyAS s4HYBg\&usg=AFQjCNHJuh7YQeoy FmwgenNi7sDBilNw\&sig2=8ETfkDY 750YkfO-b2 vRg\&bvm=bv.80642063,d.aWw

Botey, Ana. (2008). De la beneficencia a la filantropía científica: la fundación de la Gota de Leche 1913. Diálogos Revista Electrónica Escuela de Historia (Número especial) 13361377.

Recuperado http://historia.fcs.ucr.ac.cr/articulos/2008/especial2008/articulos/05-Economia/58.pdf

Campos, Mariana. (2013). La población con discapacidad en los censos de población del siglo XX en Costa Rica. Población y Salud en Mesoamérica. Revista Electrónica, 11(1), 1-43. Recuperado de http://www.redalyc.org/pdf/446/44628565001.pdf

Centeno, Fernando. (1941). La Escuela de Enseñanza Especial (Su origen, finalidad, organización y funcionamiento). San José: Imprenta Nacional.

Cordoví, Yoel. (2012). Cuerpo, pedagogía y disciplina escolar en Cuba: dispositivos de control desde discursos higienistas (1899-1958) Tzintzun. Revista de Estudios históricos, (56), 93-136. $\quad$ Recuperado de http://www.redalyc.org/articulo.oa?id=89824880004 
Costa Rica, Instituto Nacional de Estadística y Censos (INEC). (2000). IX Censo de Población de Costa Rica. San José: INEC.

Costa Rica. (1886). Ley General de Educación Común y reglamento de la misma y decreto sobre empréstito escolar. San José: Tipografía Nacional.

Costa Rica. (1914). Colección de Leyes y Decretos. Decreto Ejecutivo N N 6 del 4 de setiembre de 1914. San José: Imprenta Nacional.

Costa Rica. (1923) Colección de Leyes y Decretos. Ley № 52 Ley sobre protección social de la salud pública del 12 de marzo. San José: Imprenta Nacional.

Costa Rica. (1926). Colección de Leyes y Decretos. Decreto Ejecutivo № 2 del 2 de junio de 1926. San José: Imprenta Nacional.

Costa Rica. (1932). Ley $N^{\circ} 27$ Código de la Infancia. Sistema Nacional de Legislación Vigente (SINALEVI). Recuperado de: http://www.pgr.go.cr/Scij/

Costa Rica. (1934). La Gaceta № 145 del 28 de junio de 1934.

Costa Rica. (1940). Colección de Leyes y Decretos. Decreto Ejecutivo N ${ }^{\circ} 10$ del 23 de julio de 1940. San José: Imprenta Nacionalp.338.

Costa Rica. (1941). Colección de Leyes y Decretos. Decreto Ejecutivo N ${ }^{\circ} 26$ del 14 de noviembre de 1941. San José: Imprenta Nacional p.746.

Costa Rica. (1944). Ley $N^{\circ}$ 61. Ley constitutiva de la Escuela de Enseñanza Especial. Sistema Costarricense de Información Jurídica. Recuperado de: http://www.pgrweb.go.cr/scij/

Costa Rica. Archivo Nacional de Costa Rica ANCR. (16 de mayo de 1940). Serie Educación Pública \# 004014.

Costa Rica. Archivo Nacional de Costa Rica ANCR. (30 de julio de 1943). Serie Congreso Constitucional \# 21596.

Costa Rica. Archivo Nacional de Costa Rica ANCR. (30 de julio de 1940). Serie Educación Pública \# 2438.

Costa Rica. Archivo Nacional de Costa Rica ANCR. (30 de junio de 1941). Serie Educación Pública \# 2904.

Lachner, Vicente. (1902). Apuntes de higiene pública. Organismos, instituciones y profesiones en relación con este ramo. Revista de Costa Rica en el siglo XIX (Tomo I, pp. 187-222).

Molina, Iván. (2008). Educación y sociedad en Costa Rica: de 1821 al presente (una historia no autorizada). Diálogos Revista Electrónica de Historia, 8(2), 148-356. Recuperado de http://historia.fcs.ucr.ac.cr/articulos/2007/vol2/7vol8n2imolina.pdf 
Palmer Steven. (2005). Esbozo histórico de la medicina estatal en América Central. Dynamis, Acta Hisp. Méd. Sci. Hist. Ilus., 25, 59-85. Recuperado de: http://www.raco.cat/index.php/Dynamis/article/view/114013

Palmer Steven. (2009). "Cansancio" y Nación: el combate precoz de los salubristas costarricenses contra la anquilostomiasis. Salud Colectiva, Buenos Aires, 5(3), 403412.

Programa Estado de la Nación en Desarrollo Humano Sostenible. (2005). Estado de la Educación costarricense. San José: CONARE.

Quesada, Juan Rafael. (2005). Un siglo de educación costarricense 1814-1914. San José: Editorial de la Universidad de Costa Rica.

Rosero, Luis, Gómez, Miguel y Rodríguez, Virginia. (s.f.). Determinantes de la fecundidad en Costa Rica. Recuperado de http://ccp.ucr.ac.cr/bvp/pdf/fecundidad/rosero14.pdf

Rosero, Luis. (1985). Perfil demográfico de Costa Rica. Revista Médica. Hospital Nacional de Niños Costa Rica, 20(2). Recuperado de http://ccp.ucr.ac.cr/bvp/pdf/demografia/rosero46.pdf

Salazar, Rodolfo. (2008). Antecedente Nacional e Internacional sobre la percepción de los derechos de los niños y las niñas y las y los adolescentes. Revista EDUCARE, 12(1). Recuperado de http://www.revistas.una.ac.cr/index.php/EDUCARE/article/view/1414

Solano Vivian. (2008). La tuberculosis y el sanatorio Carlos Durán en Costa Rica (19151940). Ponencia IX Congreso Centroamericano de Historia, Costa Rica, 21-25 julio.

Velázquez, Carmela. (2006). El Dr. Carlos Durán. Su investigación médica y sus estudios sobre la niñez. En: Diálogos Revista Electrónica Volumen 7 (N¹) p 81-114. 